\title{
Las Normas Internacionales de Información Financiera y su efecto en el costo de capital
}

En los últimos años el manejo de las empresas ha tomado varios rumbos relacionados con los procesos de información, estos cambios han sido la esencia para generar la evolución de los negocios, uno de ellos ha sido la adopción de las Normas Internacionales de Información Financiera (NIIF), las cuales hacen referencia a un marco normativo con varias especificaciones tanto conceptuales y técnicas que ha cambiado el mundo de la contabilidad, otorgándole más relevancia y fiabilidad a la información financiera con el propósito de una representación total de los hechos económicos de la empresa. Es por esto que Vasco (2013) la define como un "conjunto de normas e interpretaciones de carácter técnico, aprobadas, emitidas y publicadas por el Consejo de Normas Internacionales de Contabilidad".

La aplicación de esta normatividad otorga un mayor grado competencia y homogeneidad a nivel empresarial, debido a la estructuración de un idioma financiero y contable que sea hablado a nivel global y de esta forma sea comprensible en todo ámbito. Otro de los grandes puntos por el cual las NIIF son necesarias en las empresas es la facilidad en la adquisición de inversión externa y la reducción del costo de capital, debido a que se tiene una mayor claridad en la información destinada a las partes interesadas. Esta reducción del costo de capital es importante para la financiación de las entidades debido a que a menor costo mayor rentabilidad para la empresa y por tal motivo va a ser mayor su crecimiento financiero.

Para entender este concepto se parte de que El costo capital es el rendimiento promedio requerido por los inversionistas de la empresa para determinar cuál es la cantidad que debe pagarse para atraer fondos, 
dicho de otras palabras es el valor que una empresa deberá pagar por medio de rendimientos a los inversores.

Uno de los estudios que está adelantando la facultad de contaduría pública y que es tema relevante en la investigación a nivel global está relacionado con el estudio de analizar el efecto que tiene la aplicación de las NIIF en la disminución o el aumento del costo capital.

A continuación, se presenta un cuadro con las implicaciones NIIF/Costo capital de los diferentes países estudiados con algunas empresas adoptantes.

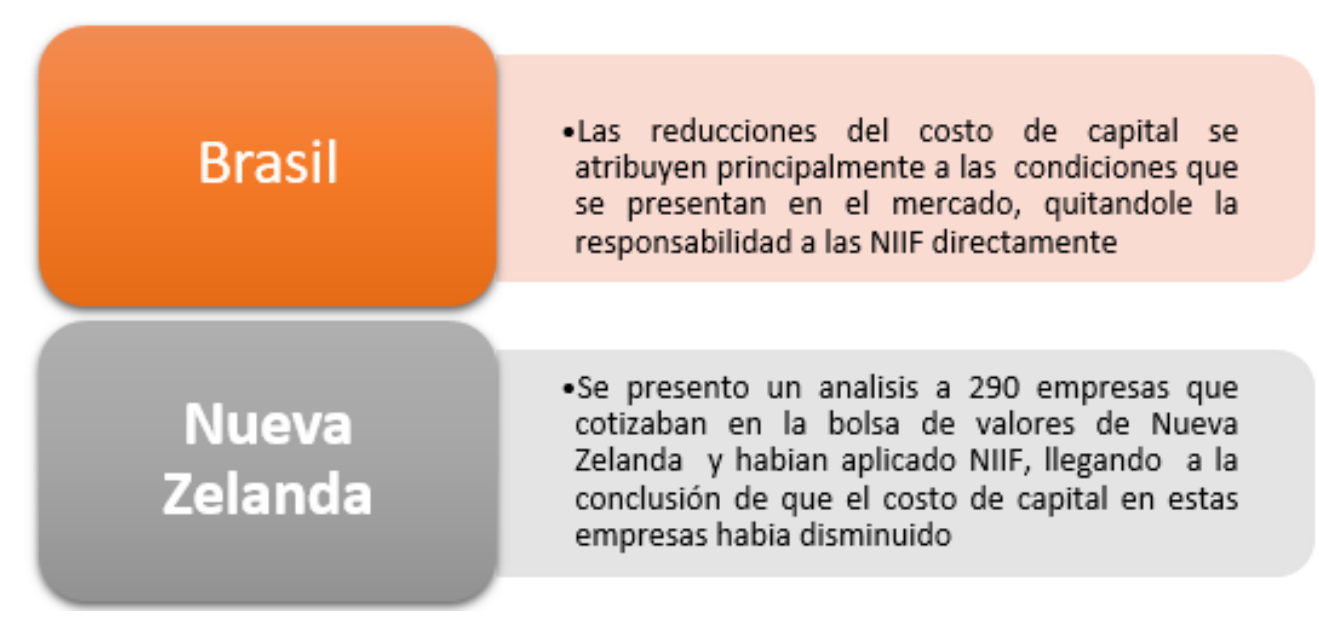

Ilustración 1 Principales estudios sobre el efecto de las NIIF en el costo de capital 
- En una muestra que involucra 1084 empresas pertenecientes a la Unión Europea, llegando al resultado de que la reducción del costo de capital va a estar relacionado directamente con el nivel de exigencia en la adopcion de NIIF

\section{Alemania}

-Adoptaron NIIFy USGAAP

- Existe un menor riesgo a la hora de invertir en las empresas debido a que no dependian solamente de las NIIF

-Afirman de igual manera que la aplicación de NIIF genera una reducción en el costo de Capital

Rumania - Se resalta que la aplicacion de las NIIF y la información que esta generara un mejor acceso a los mercados internacionesles y una mayor oportunidad de recibir inversión extranjera

-Aplicación de normatividad internacional impulsada por el gobierno

Australia

- Se establece que la implementacionde las NIIF permitira un acceso a los mercados internacionales, mejor calidad de la información y reduccion del costo de capital

\section{Colombia}

- Enfocados en el sector de pymes se puede concluir que el costo de capital de las pymes de acuerdo a estudios realizados en los ultimos 10 años a ido incrementando 
Estos estudios realizados demuestran que las NIIF representan un menor costo de capital lo cual facilita la captación de recursos, esto significa mayor musculo de capital para desempeñar operaciones. Adicional a esto es importante aclarar que esto no solamente se da gracias a la aplicación de este marco normativo, también está asociado a un buen mercado de capitales, un ente regulador que se encargue de vigilar la aplicación adecuada de la norma, entre otras buenas prácticas.

\section{Autores}

Iván Camilo Montoya Valencia

Edgar Alejandro Pérez castro

Miguel Angel Laverde Sarmiento

\section{Bibliografía}

Besley. (2001). 23.

Vasco, F. (8 de Marzo de 2013). Noticias de la Cámara de Medellin. Obtenido de Cámara de Medellín: http://www.camaramedellin.com.co/site/Noticias/Semana-

Actualizacion-Tributaria-Afiliados.aspx 


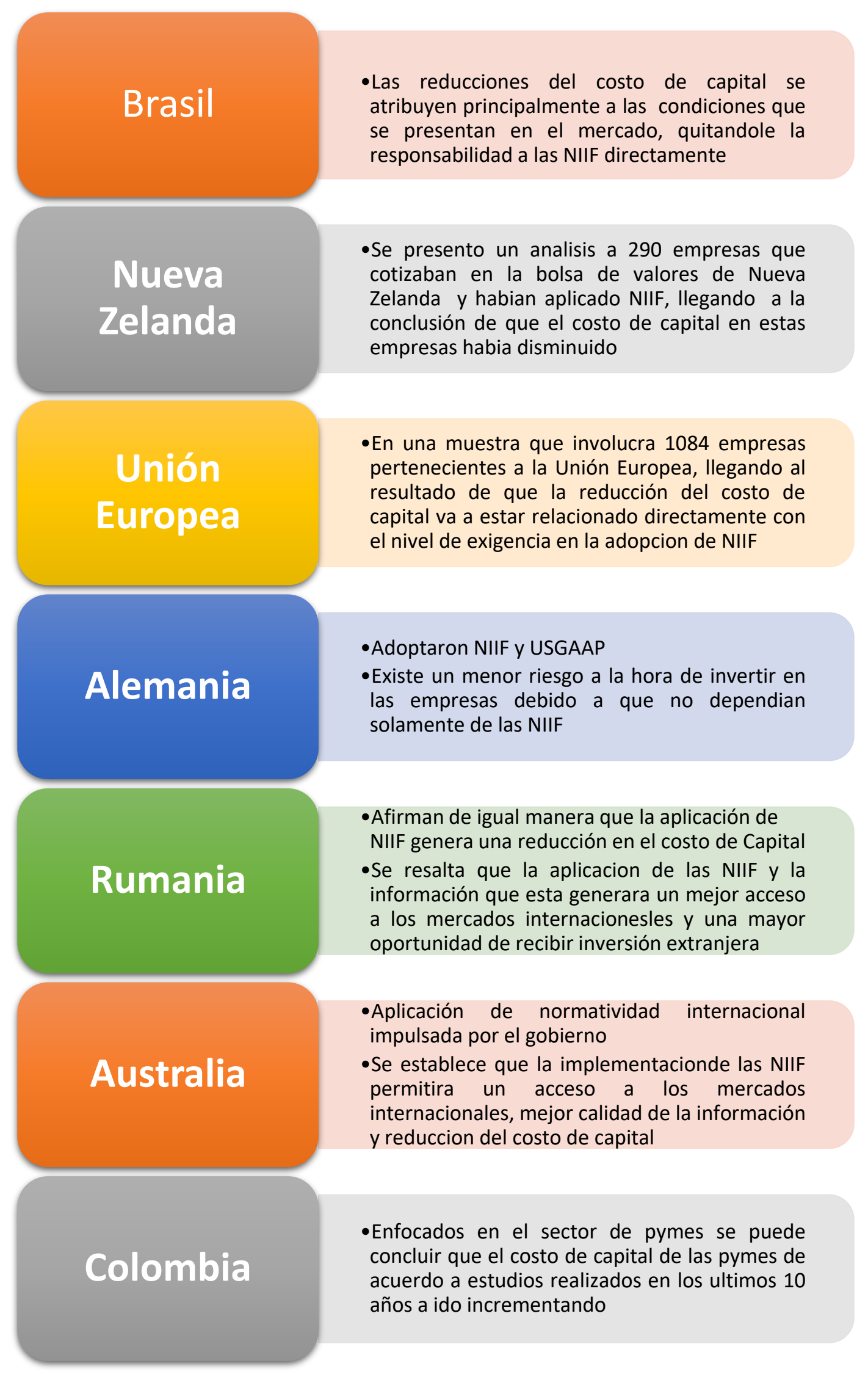

